\title{
Improving Injectable Medicines Prescription in Outpatient Services: A Path Towards Rational Use of Medicines in Iran
}

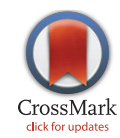

\author{
Firoozeh Bairami $^{1}$, Fatemeh Soleymani ${ }^{2,3}$, Arash Rashidian ${ }^{1,4^{*}}$
}

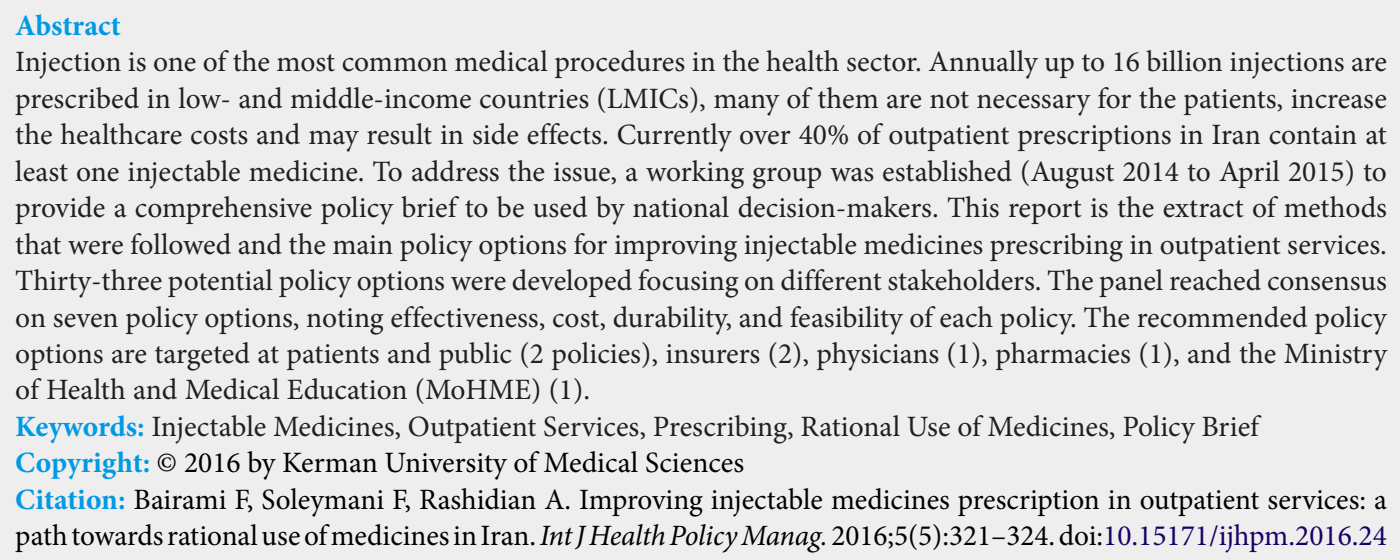

Injection is one of the most common medical procedures in the health sector. Annually up to 16 billion injections are prescribed in low- and middle-income countries (LMICs), many of them are not necessary for the patients, increase the healthcare costs and may result in side effects. Currently over $40 \%$ of outpatient prescriptions in Iran contain at least one injectable medicine. To address the issue, a working group was established (August 2014 to April 2015) to provide a comprehensive policy brief to be used by national decision-makers. This report is the extract of methods that were followed and the main policy options for improving injectable medicines prescribing in outpatient services. Thirty-three potential policy options were developed focusing on different stakeholders. The panel reached consensus on seven policy options, noting effectiveness, cost, durability, and feasibility of each policy. The recommended policy options are targeted at patients and public (2 policies), insurers (2), physicians (1), pharmacies (1), and the Ministry of Health and Medical Education (MoHME) (1).

Keywords: Injectable Medicines, Outpatient Services, Prescribing, Rational Use of Medicines, Policy Brief

Copyright: (C) 2016 by Kerman University of Medical Sciences

Citation: Bairami F, Soleymani F, Rashidian A. Improving injectable medicines prescription in outpatient services: a path towards rational use of medicines in Iran. Int J Health Policy Manag. 2016;5(5):321-324. doi:10.15171/ijhpm.2016.24

\section{Article History:}

Received: 23 August 2015 Accepted: 23 February 2016 ePublished: 5 March 2016

\section{*Correspondence to: \\ Arash Rashidian}

Email: arashidian@tums.ac.ir

\section{Statement of the Issue and Background}

Rational use of medicines is an important component of an effective health system. ${ }^{1}$ According to the World Health Organization's (WHO's) definition, rational use of medicines means "patients receive medications appropriate to their clinical needs, in doses that meet their own individual requirements, for an adequate period of time, and at the lowest cost to them and their community" ${ }^{2}$ but when the use of medicines is not compatible to the components of above-mentioned definition, the problem of irrational use of medicine does happen. ${ }^{3}$ Excessive use of antibiotics, overuse of injections rather than oral formulations, and not taking the full course of medications are among the most common types of inappropriate use of medicines. ${ }^{4}$ The magnitude of problem in overuse of injections and antibiotics is vast and worldwide and it is much more common in low- and middleincome countries (LMICs). ${ }^{5}$

Injection is one of the most common medical procedures in the health sector. Annually up to 16 billion injections are prescribed in LMICs. In some setting, over $70 \%$ of injections are unnecessary or can be given in other formulations like oral medications. ${ }^{6}$ Injection is an invasive procedure which can lead to some side effects including bleeding, inflammation, atrophy, nerve injury, and in some cases hypersensitivity reactions such as anaphylactic shock. ${ }^{7}$ Moreover, high rates of injection can increase the risks of spreading blood borne diseases such as hepatitis B, C, and $\mathrm{HIV}^{8}$ and incur unnecessary economic burden and costs on users and the health system..$^{9,10}$ Injections should preferably be used in circumstances when safer delivery options (usually oral formulations) of medications are not available or if the patient is not to able to use oral formulations. This issue can be applied more stringently to outpatient settings where by definition patients need less injectable medicines. ${ }^{11}$

\section{Current Situation}

According to the WHO's estimation the average rate of injections per person per year is about 3.4 in LMICs. ${ }^{12} \mathrm{~A}$ review in 1999 by the World Bank noted that 25\%-96\% of outpatient prescriptions in eight countries contained at least one injection. ${ }^{8}$ In another review that was conducted in 2000 based on 14 regional division defined by the global burden of disease project of the WHO, in the 10 regions (four predominantly affluent, developed regions excluded) the annual rate of injections per person ranged from 1.7 to 11.3. ${ }^{13}$ More recent reports from countries confirm the high rate of injections. A study from Bangladesh reported more than $75 \%$ of patients received injection. ${ }^{14}$ This rate for Korea in 2004 was 30.9\%. ${ }^{15}$ India and Cambodia reported 2.9 and 5.9 injections per person per year, respectively. ${ }^{16,17}$

Studies in Iran reveal that the rate of injections is high. This rate in a study conducted in 2009 was $58 \%{ }^{18}$ and in another study the percentage was reported $41 \%{ }^{19}$

In 1997 to embed the concept of the rational use of medicines in health system body and to improve the standards of prescription issuance, the National Committee for Rational Use of Drug was established with 44 branches in medical universities across the country. Even though the committee and its subcommittees are working for more than 17 years, yet the rate of injections did not fall within the target range. According to the last report of committee, the rate of injection was estimated at $41 \%{ }^{20}$ To address the issue, a working group was established to provide a comprehensive policy brief. This report is the extract of methods that were followed and the main policy options for improving injectable medicines prescribing in outpatient services.

\section{Options Extraction}

The policy brief reports the processes and results of a policy 
development initiative to identify feasible interventions to reduce prescriptions including injectable medicines in outpatient services. The process involved targeted reviews of the literature, key informant consultations, open discussions within the working group, and a consensus development process using nominal group technique.

\section{Targeted Review of Literature}

We searched the relevant literature to detect current scientific literature referring to the injectable medicines prescribing in outpatient services. The search was performed via online resources using the following research platforms: PubMed, Google Scholar, and Cochrane Library. We also reviewed pharmacology textbooks and WHO guidance ${ }^{21,22}$ for finding guidelines regarding injectable medicines prescribing in outpatient services.

\section{Informant Consultations}

In order to consider all factors leading to prescribe/use injectable medicines as much as possible, and also to consider unpublished reports, we interviewed five key informants. Four out of five had key positions in the health system and one had conducted an unpublished study regarding injection prescribing practices in the country.

\section{Open Discussions Within the Working Group}

To finalize the leading factors and to provide policy options the working group held open discussion sessions with all stakeholders attending the meeting. The participants suggested policy options according to their background.

\section{Consensus Development}

Accordingly, policy options were provided for each factor.
Then in next step, the working group followed a nominal group technique approach to reach consensus on policy options based on four dimensions including effect, cost, durability, and feasibility of different options. In the final step, percentages of each item were calculated and results categorized in 3 domains: low, medium, and high support. Each intervention (policy option) that received the highest votes of support was taken into account for implementation. The working group also discussed different interventional approaches for changing professional behavior. ${ }^{23,24}$

\section{Working Group Member and Setting}

The working group comprised of 10 key experts representing important stakeholders, including Food and Drug Organization, Health Insurance Organizations, Medical Council Organization relevant academics, researchers, and representatives of pharmacists.

\section{Results}

The working group identified 33 policy options considering four dimensions including effect, cost, durability, and feasibility of each option (Additional file 1) the dimensions were extracted from a previous extensive work on categorization of intervention to change professional behavior. ${ }^{23}$ After scoring to each item, seven policy options selected for implementing. The results were summarized in Table. We used the format of a published policy brief for shaping and reporting our final options. $^{25}$

\section{Discussion}

The high rate of prescribed injections as one of the most considerable problems is now on our health policy-makers' agenda. Even though the magnitude of the problem is known,

Table. Policy Options

\begin{tabular}{|c|c|c|}
\hline Policy Options & Policy Description & Advantages/Disadvantages \\
\hline $\begin{array}{l}\text { 1. Developing evidence-based clinical } \\
\text { guidelines containing recommendations for } \\
\text { appropriate prescribing }\end{array}$ & $\begin{array}{l}\text { This policy option targets doctors and is designed } \\
\text { in response to a perceived lack of knowledge about } \\
\text { effective alternative methods for patient management. }\end{array}$ & $\begin{array}{l}\text { This Policy has a low implementing cost }- \text { is } \\
\text { expected to have a modest effect for a reasonable } \\
\text { period of time. Its feasibility is acceptable. }\end{array}$ \\
\hline $\begin{array}{l}\text { 2. Enforcing the regulations for dispensing of } \\
\text { non-prescription medicines }\end{array}$ & $\begin{array}{l}\text { In response to providing injectable medicines without } \\
\text { prescription. It is aimed at pharmacies. }\end{array}$ & $\begin{array}{l}\text { The cost of implementing this policy is low with a } \\
\text { good effect in reasonable period of time. However, } \\
\text { the feasibility of implementing it is low. }\end{array}$ \\
\hline $\begin{array}{l}\text { 3. Using mass media to increase public } \\
\text { awareness regarding side effects of injection }\end{array}$ & $\begin{array}{l}\text { Public may demand injectable medicines. Using mass } \\
\text { media can Increase awareness of a large number of } \\
\text { people. }\end{array}$ & $\begin{array}{l}\text { We expect a small effect from this policy, effective } \\
\text { use of mass media might be costly. The durability } \\
\text { and feasibility of implementing is reasonable. }\end{array}$ \\
\hline $\begin{array}{l}\text { 4. Interventions to change public attitude } \\
\text { toward reducing injectable medicines } \\
\text { demand }\end{array}$ & $\begin{array}{l}\text { Because of lack of knowledge people think injecteble } \\
\text { medicines are more effective than other form of } \\
\text { medicines. In this regard, increasing knowledge is useful } \\
\text { which is possible with changing public attitude. }\end{array}$ & $\begin{array}{l}\text { We can implement this policy easily with a low cost } \\
\text { but as the target group is the whole society and the } \\
\text { policy is not personalized the effect is low and will } \\
\text { decrease during time. }\end{array}$ \\
\hline $\begin{array}{l}\text { 6. Changing the policy of auditing the } \\
\text { number of medicinal items in each } \\
\text { prescription to the content of prescriptions } \\
\text { (interactions, effectiveness, relevance) }\end{array}$ & $\begin{array}{l}\text { Insurers can check the content of a prescription to } \\
\text { watch which form of medicines have been prescribed } \\
\text { rather than to check the number of medicinal items (The } \\
\text { current policy is to count the number of medicines). }\end{array}$ & $\begin{array}{l}\text { Implementing this policy can be considered as a } \\
\text { rational choice because with a reasonable cost we } \\
\text { will have a very good effect in a long period of time. }\end{array}$ \\
\hline $\begin{array}{l}\text { 7. Developing clear guidance for use of } \\
\text { injectable medicines in outpatient settings }\end{array}$ & $\begin{array}{l}\text { MoHME as the main policy-maker in the country can } \\
\text { control the issue by developing proper guidelines } \\
\text { regarding injection. }\end{array}$ & $\begin{array}{l}\text { This policy can be implemented easily by a } \\
\text { reasonable cost. However, its effect is low and it } \\
\text { can last for a long period of time. }\end{array}$ \\
\hline
\end{tabular}

Abbreviation: MoHME, Ministry of Health and Medical Education. 
there is a big gap in literature regarding the effectiveness of interventions that can be used to reduce prescriptions containing injectable medicines. We could not find any explicit criteria in pharmacology textbook ${ }^{21}$ regarding the standard number of prescribing injections or the condition that we should prescribe injections particularly in outpatient services, although WHO's handbook for good prescription has recommended that less $10 \%$ of outpatient prescriptions should contain injectable medicines. ${ }^{22}$ We identified 13 stakeholders (Figure) which seven of them were considered as the main stakeholders and the others as the secondary stakeholders. The interventions were targeted at these stakeholders to guide implementation processes.

The panel reached consensus on seven policy options, noting effectiveness, cost, durability, and feasibility of each policy. To categorize the interventions, we used a previously developed conceptual framework ${ }^{23}$ which classifies the interventions to two types including voluntary and non-voluntary (obligatory) interventions. Voluntary interventions include the interventions that target providers' internal or external motivations. Such categorization helps to define the policies so that both the personal attributes and environmental factors are considered when the interventions are designed and implemented.

We also suggested intervention by targeting stakeholders in this process. The majority of previous studies which have been conducted regarding injections, mainly have considered issues associated to patients such as their beliefs in order to faster and better effect of injection in comparison to oral formulations, lack of awareness regarding the side effects of injections, and socio-cultural factors ${ }^{7,11,26,27}$ that cause patients asks their doctors to prescribe injectable medicines. The other studies considerably highlight some factors related to doctors, including economic and financial reasons, competition and pressure from third parties (pharmacies, injection units, and patients) $)^{7,14,28,29}$ that have been taking into account as the main factors drive them to prescribe injectable medicines regardless of actual indications.

le Grand and colleagues define another classification of interventions in this regard which includes educational, managerial, and financial policy options. ${ }^{30}$ According to the literature review, researchers mostly focus on educational options $^{5,26}$ and their effectiveness in reducing use of injections. ${ }^{31}$ Educational options refer to train people via mass media, schools or group discussion, continuous medical education for doctors and developing related educational curriculum in schools of pharmacy and medicine. Interactive group discussions can be more effective educational strategies to decrease the rate of unnecessary injections. ${ }^{31,32}$ Briefly, empowering people and changing their beliefs and norms regarding overuse of injections may sound time taking process but it can be useful. ${ }^{4}$

But there are other leverages that we have considered as policy option in the category of managerial, like monitoring (doctors, pharmacies, and injection units), restricting pharmaceutical list, developing guidelines, restricting delivery of over the counter medicines and revision of existing interventions. Financial interventions include provision of insurance coverage of injectable medicines (which will enable regulatory oversight of their use by insurance organizations), removing doctor-patient financial relation by capitation payment and elimination of financial incentives in provision of injection services by doctors. ${ }^{33}$

The priority of implementation of policy options preferably is like managerial and educational, respectively. ${ }^{30,31}$ This is what our report shows too.

The financial policy options were not in favorable position to be implemented. It seems the same is applicable in other settings. ${ }^{30,34}$

The main limitation of our study was the lack of previous studies regarding appropriate interventions in this field. There are a lot of studies regarding injection safety but we rarely could find studies about the interventions to reduce injections rate.

\section{Conclusion}

Reducing use of injectable medicines in outpatient settings is affected by different factors and stakeholders. Effective reduction in such inappropriate usage of medicines needs persistency in policy-making and implementation and clear

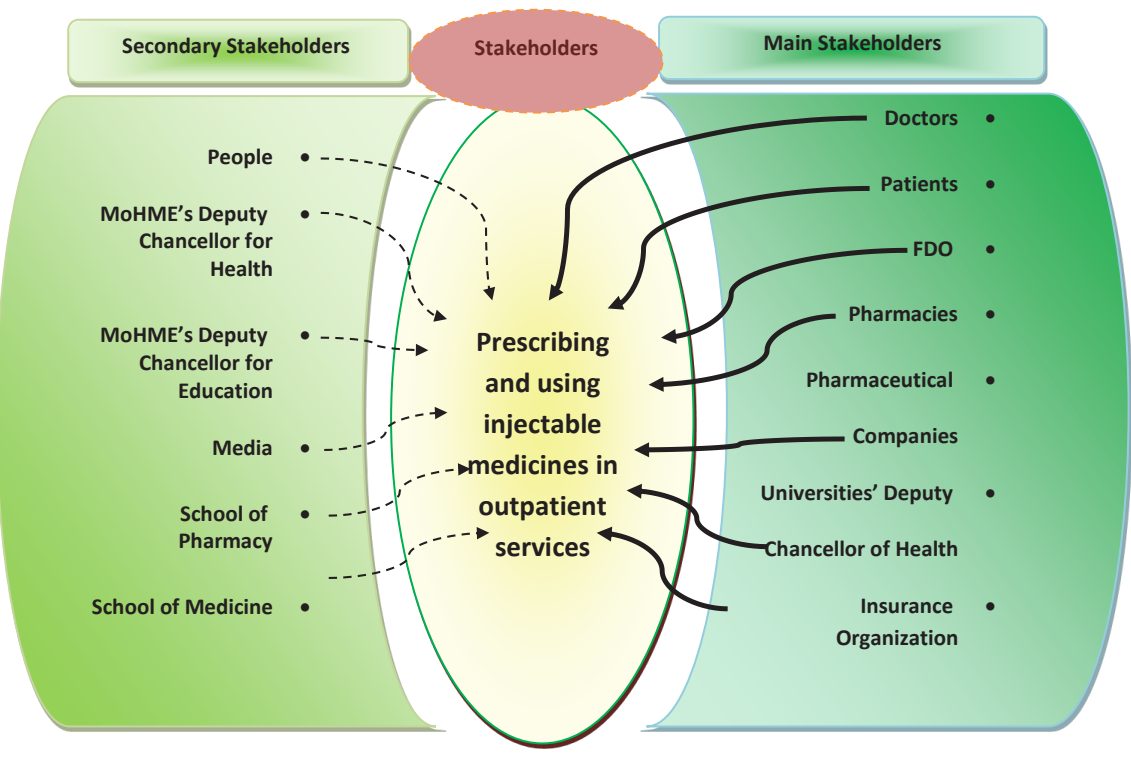

Figure. Main Stakeholders of Prescribing and Using Injectable Medicines in Outpatient Services. FDO, Food and Drug Organization. 
attention in legitimate concerns of the different stakeholders.

Acknowledgments

We would like to thank Dr. Nooshin Mohammad Hosseini, Dr. Bita Mesgarpour, Dr. Forouzan Taheri, Dr. Raziye Keshavarz, Dr. Amir Sarayani, and Dr. Keyvan Tajbakhsh for their time and valuable recommendations in this project. We also are grateful to the anonymous reviewers for insightful comments.

\section{Ethical issues}

Not applicable.

\section{Competing interests}

Authors declare that they have no competing interests.

\section{Authors' contributions}

AR and FS designed the study, FB drafted manuscript. AR and FB finalized the draft.

\section{Authors' affiliations}

'Department of Health Management and Economics, School of Public Health, Tehran University of Medical Sciences, Tehran, Iran. ${ }^{2}$ Department of Pharmacoeconomics and Pharmaceutical Administration, Faculty of Pharmacy, and Pharmaceutical Economics and Decision-Making Research Center, Tehran University of Medical Sciences, Tehran, Iran. ${ }^{3}$ National Committee on Rational Medicine Use, Food and Drug Administration, Ministry of Health and Medical Education, Tehran, Iran. ${ }^{4}$ Department of Global Health and Public Policy, School of Public Health, Tehran University of Medical Sciences, Tehran, Iran.

\section{Additional files}

Additional file 1: Contains the Appendix 1

\section{References}

1. Khan M, Ara N. Promoting rational prescribing among medical practitioners. Bangladesh Med J. 2014;40(2):6-7.

2. World Health Organization (WHO). The Rational use of drugs: report of the conference of experts, Nairobi, 25-29 November 1985. Geneva: World Health Organization; 1987.

3. World Health Organization (WHO). Promoting rational use of medicines: core components. Geneva: WHO; 2002.

4. Roberts MJ. Pharmaceutical reform: a guide to improving performance and equity. World Bank Publications; 2011.

5. Rashidian A, Zaidi S, Jabbour S, Soleymani F, Jahanmehr N. Identification of priority policy research questions in the area of access to and use of medicines in EMRO Countries. http://www. who.int/alliance-hpsr/projects/alliancehpsr_iranlebanonpakistan_ atmps.pdf. Published June 2011.

6. Against all reason: misuse and overuse of injections. WHO website. http://www.who.int/injection_safety/about/resources/Misuse/en/. Accessed January 14, 2015.

7. Choi KH, Park SM, Lee JH, Kwon S. Factors affecting the prescribing patterns of antibiotics and injections. J Korean Med Sci. 2012;27(2):120-127. doi:10.3346/jkms.2012.27.2.120

8. Sirnonsen L, Kane A, Lloyd J, Zaffran M, Kane M. Unsafe injections in the developing world and transmission of blood-bome pathogens. Bull World Health Organ. 1999;77:789-800.

9. Miller M, Pisani E. The cost of unsafe injections. Bull World Health Organ. 1999;77:808-811.

10. Wyatt $\mathrm{H}$, Mahadevan $\mathrm{S}$. Unnecessary injections in developing countries: the risk and costs. Int J Risk Saf Med. 1993;4(2):167-176. doi:10.3233/JRS-1993-4206

11. Sohn HS, Jang S, Han E, Lee EJ, Shin SA, Lee JY. Patient factors affecting frequent potential unnecessary injection use in outpatient care setting. Arch Pharm Res. 2015;38(7):1389-1396. doi:10.1007/ s12272-014-0406-5

12. Technical activities: Injection safety. WHO website. http://www.who. int/patientsafety/activities/technical/injection_safety/en/. Accessed February 27, 2015.

13. Hutin YJ, Hauri AM, Armstrong GL. Use of injections in healthcare settings worldwide, 2000: literature review and regional estimates. BMJ. 2003;327(7423):1075.

14. Chowdhury AA, Roy T, Faroque A, et al. A comprehensive situation assessment of injection practices in primary health care hospitals in Bangladesh. BMC Public Health. 2011;11:779. doi:10.1186/14712458-11-779

15. Kim DS, Hwang JH, Hwang Jl. A multi-level analysis of injection requests and associated patient characteristics in the Korean acutecare outpatient setting. Kor J Clin Pharm. 2012;22(1):13-20.

16. IPEN Study Group. Injection practices in India. WHO South-East Asia Journal of Public Health 2012;1(2):189-200.

17. Vong S, Perz JF, Sok S, et al. Rapid assessment of injection practices in Cambodia, 2002. BMC Public Health. 2005;5:56.

18. Garjani A, Salimnejad M, Shamsmohamadi $M$, et al. Effect of interactive group discussion among physicians to promote rational prescribing. East Mediterr Health J. 2009;15(2):408-415.

19. Cheraghali AM, Nikfar S, Behmanesh $Y$, et al. Evaluation of availability, accessibility and prescribing pattern of medicines in the Islamic Republic of Iran. East Mediterr Health J. 2004;10(3):406415.

20. The Ministry of Health and Medical Education (MOHME) of Iran. http://fdo.behdasht.gov.ir/uploads/114_1363_8_iran90.pdf.

21. Katzung BG, Masters SB, Trevor AJ. Basic \& Clinical Pharmacology. New York: McGraw-Hill; 2004.

22. Hogerzeil HV, Barnes KI, Henning R, et al. Teacher's guide to good prescribing. Geneva: WHO; 2001.

23. Rashidian A. Study of adherence to guidelines and evidence (SAGE): theory-based analyses of beliefs, attitudes and prescribing outcomes in British primary care. UK: University of York; 2004.

24. Wensing M, Grol R. Single and combined strategies for implementing changes in primary care: a literature review. Int J Qual Health Care. 1994;6(2):115-132.

25. Ongolo-Zogo P, Bonono RC. Policy brief on improving access to artemisinin-based combination therapies for malaria in Cameroon. Int J Technol Assess Health Care. 2010;26(2):237-241. doi:10.1017/ S0266462310000188

26. Mclaws ML, Ghahramani S, Palenik CJ, Keshtkar V, Askarian M. Assessment of injection practice in primary health care facilities of Shiraz, Iran. Am J Infect Control. 2014;42(3):300-304. doi:10.1016/j. ajic.2013.09.006

27. Raglow GJ, Luby SP, Nabi N. Therapeutic injections in Pakistan: from the patients' perspective. Trop Med Int Health. 2001;6(1):69-75.

28. Shatsky M. Evidence for the use of intramuscular injections in outpatient practice. Am Fam Physician. 2009;79(4):297-300.

29. Hwang JH, Kim DS, Lee SI, Hwang JI. Relationship between physician characteristics and their injection use in Korea. Int J Qual Health Care. 2007;19(5):309-316.

30. le Grand A, Hogerzeil HV, Haaijer-Ruskamp FM. Intervention research in rational use of drugs: a review. Health Policy Plan. 1999;14(2):89-102.

31. Hadiyono JE, Suryawati S, Danu SS, Santoso B. Interactional group discussion: results of a controlled trial using a behavioral intervention to reduce the use of injections in public health facilities. Soci Sci Med. 1996;42(8):1177-1183.

32. Sarayani A, Rashidian A, Gholami K, Torkamandi H, Javad M. Efficacy of continuing education in improving pharmacists' competencies for providing weight management service: threearm randomized controlled trial. J Contin Educ Health Prof. 2012;32(3):163-173. doi:10.1002/chp.21141

33. Naeemeh Yousefi AR, Soleymani F, Kebriaeezade A. Relationship between the provision of injection services in ambulatory physician offices and prescribing injectable medicines. Iran $J$ Pharm Res. 2016; Forthcoming.

34. Chen M, Wang L, Chen W, Zhang L, Jiang H, Mao W. Does economic incentive matter for rational use of medicine? China's experience from the essential medicines program. Pharmacoeconomics. 2014;32(3):245-255. doi:10.1007/s40273-013-0068-z 